\title{
CONTRIBUCIÓN AL ESTUDIO DE LA DIFUSIÓN DE LA COSMOGRAFÍA DE JULIO HONORIO EN LA PENÍNSULA IBÉRICA*
}

\author{
Mayte PENELAS \\ CSIC. Granada
}

\section{INTRODUCCIÓN}

Hace ya un cuarto de siglo fue publicado el artículo de M. C. Díaz y Díaz «La Cosmografía de Julio Honorio en la Península» ${ }^{1}$; desde entonces, que yo sepa, nadie ha vuelto a estudiar la difusión peninsular de este tratado geográfico. Partiendo del texto procedente de la Cosmografía de Julio Honorio ${ }^{2}$ inserto en el Códice Ovetense de El Escorial, R.II.18 ${ }^{3}$, Díaz y Díaz observaba la estrecha relación entre la versión que ofrece este códice y las de los demás testimonios hispanos de la Cosmografía: la Crónica de Albelda ${ }^{4}$, «la síntesis historiográfica oro-

* Quiero expresar mi agradecimiento a M. Luisa Ávila, Charles Burnett, Expiración García y Luis Molina por su ayuda y siempre valiosas sugerencias. Este trabajo se llevó a cabo antes de que fuera publicada la nueva edición de la Crónica Pseudo Isidoriana realizada por F. González Muñoz (La chronica gothorum pseudo-isidoriana [ms. Paris BN 6113], La Coruña, 2000). Esta edición revisa y, sin duda, mejora la de Mommsen de 1892 (la de A. Benito Vidal, publicada en 1961, es mera reproducción de la de Mommsen). No obstante, he comprobado que la nueva edición coincide con la anterior en los datos que nos interesan aquí y, por tanto, los resultados y conclusiones de este trabajo no se ven alterados.

${ }^{1}$ En Classica et Iberica. A Festschrift in Honor of the Reverend Joseph M.-F. Marique, ed. P. T. Brannan, Worcester Mass., 1975, 331-338.

2 Ed. A. Riese, en Geographi Latini minores, Heilbronn, 1878, 21-55.

${ }^{3}$ Este códice contiene varios textos, la mayor parte de ellos geográficos, escritos entre el siglo VII, o principios del VIII, y el IX. Para una descripción del códice véase, por ejemplo: Antolín, G., Catálogo de los códices latinos de la Real Biblioteca de El Escorial, Madrid, 1910-1923, vol. III, 481-487; id., «El Códice Ovetense de la Biblioteca del Escorial», La Ciudad de Dios, 108 (1917), 20-33; id., «El Códice Ovetense de la Biblioteca del Escorial», La Ciudad de Dios, 110 (1917), 59-67; Millares Carlo, A., Manuscritos visigóticos. Notas bibliográficas, Barcelona, 1963, n. ${ }^{\circ}$ 29; id., Corpus de códices visigóticos, ed. M. C. Díaz y Díaz, A. M. Mundó, et al., Las Palmas de Gran Canaria, 1999, n. ${ }^{\circ}$ 60; Díaz y Díaz, M. C., «El Códice Ovetense del Escorial», en Códices visigóticos en la monarquía leonesa, León, 1983, 17-53.

${ }^{4}$ Chronicon Albeldense, ed. E. Flórez, en España Sagrada, XIII, Madrid, 1782, 433-466; Chronique d'Albelda, ed. y trad. Y. Bonnaz, en Chroniques Asturiennes (fin IX siècle), París, 1987, 10-30. Los manuscritos más importantes que se conservan de la Crónica de Albelda son el Albeldense del s. x (Biblioteca de El Escorial, d.I.2), el Emilianense del s. x (Biblioteca de la Real Academia de la Historia de Madrid, n. ${ }^{\circ}$ 39), y el Complutense del s. XII (Biblioteca Nacional de Madrid, ms. 1358). Sobre los mss., véase Bonnaz, Y., Chroniques Asturiennes, XXIX-XXXI. Véase también Flórez, España Sagrada, XIII, 417 y ss.; Gómez-Moreno, M., «Las primeras 
siana traducida al árabe», y la Crónica Pseudo Isidoriana ${ }^{5}$, a la que no presta atención «por su data tardía y por depender en este aspecto de la síntesis árabe», dice Díaz y Díaz ${ }^{6}$. Por entonces, ya había sido descubierto el manuscrito de la Universidad de Columbia $(\mathrm{X}, 893.712 \mathrm{H})$ que contiene la traducción árabe de las Historiae adversus paganos de Orosio (primera mitad del s. v) ${ }^{7}$ realizada a fines del siglo IX o principios del $\mathrm{x}$, pero aún no había salido a la luz la edición de 'Abd al-Raḥmān Badawī ${ }^{8}$. Por tanto, Díaz y Díaz no pudo disponer del Kitāb Hurūšsiyūš - título con el que es conocida comúnmente la traducción árabe de las Historias de Orosio- para confrontar la versión que ofrece este texto con las del códice Ovetense, la Crónica de Albelda y la Crónica Pseudo Isidoriana. Como veremos más adelante, para demostrar la «innegable vinculación» entre las versiones del $K$. Hurūšiyūš y de los otros, Díaz y Díaz se basaba en un único dato coincidente entre ellos en contra de los otros testimonios de la Cosmografía, dato que tomó del artículo de Levi Della Vida «La traduzione arabe delle Storie di Orosio» ${ }^{9}$.

Crónicas de la Reconquista: el ciclo de Alfonso III», BRAH 100 (1932), 562-628; artículos de C. Sánchez-Albornoz sobre la Crónica de Albelda reunidos en Investigaciones sobre historiografía hispana medieval: siglos VIII al XII, Buenos Aires, 1967.

5 Historia Pseudoisidoriana, ed. Th. Mommsen, en Chronica minora, II (MGH Auct. Ant., XI), Berlín, 1892, 378-388; Crónica Seudo Isidoriana, ed. A. Benito Vidal, Valencia, 1961. La Crónica Pseudo Isidoriana, de la que se conserva un único manuscrito del siglo XIII (códice 6113 de la Biblioteca Nacional de París), es, al parecer, traducción latina de un original árabe compuesto en la primera mitad del siglo x (véase Levi Della Vida, G., «The 'Bronze Era' in Moslem Spain», JAOS 63 [1943], 186, n. 27 [rep. en Note di storia letteraria arabo-ispanica, ed. M. Nallino, Roma, 1971, 115, n. 28]; Menéndez Pidal, R., «Sobre la Crónica Pseudo Isidoriana», CHE 21-22 [1954], especialmente 10-13). Sobre la Pseudo Isidoriana, véase también la introducción de Th. Mommsen a su edición y el artículo de C. Sánchez-Albornoz, «San Isidoro, 'Rasis' y la Pseudo Isidoriana», CHE 4 (1946), 73-113.

6 «La Cosmografía de Julio Honorio en la Península», 338.

7 Sobre el hallazgo del manuscrito, véase Martinovitch, N. N., «Arabic, Persian and Turkish Manuscripts in the Columbia University Library», JAOS 49 (1929), n. 18; id., "Crusius or Orosius», JAOS 51 (1931), 171-172; Levi Della Vida, G., reseña del libro de Ph. Hitti History of the Arabs (Londres, 1937), publicada en JAOS 59 (1939), especialmente 125.

${ }^{8}$ Ūrūsiyūs, Ta'rīj al-'álam, Beirut, 1982. En este caso, Badawī no dispuso de la fuente latina para «enmendar» el texto árabe. Como hace con el texto procedente de la obra de Orosio, si hubiera tenido a su disposición la Cosmografía, en su edición Badawī probablemente habría modificado el texto árabe que ha llegado hasta nosotros de manera que se asemejara lo más posible al texto original de la Cosmografía. No obstante, la edición de Badawi contiene numerosas lecturas - los nombres propios principalmente- que no se corresponden con la lección que da el manuscrito de Columbia. En estos momentos se encuentra en curso de publicación mi edición del texto (Kitāb Hurūšiyū̌̌s, Madrid, CSIC, en prensa), que pretende ser más respetuosa hacia el único manuscrito conservado. Dado que aún no ha sido publicada esta nueva edición, en este trabajo se remite, en primer lugar, a la página del manuscrito (según tanto la foliación del manuscrito, que responde al orden actual de los folios, como la numeración de las páginas en mi edición, que responde al orden real) y, a continuación, al número de párrafo tal como aparecerá en mi edición.

9 En Miscellanea G. Galtiati, vol. III, Milán, 1951, 185-203; publicado con correcciones y adiciones en Al-Andalus 19 (1954), 257-293 (rep. en Note di storia letteraria arabo-ispanica, 79-107). 
Durante los años que he dedicado al $K$. Hurūšyuūš, en varios momentos he podido comprobar el interés de este texto para el estudio de la Cosmografía de Julio Honorio, pero hasta ahora no había tenido la oportunidad de realizar un estudio en profundidad sobre esta cuestión. En este trabajo expondré los resultados obtenidos de la comparación exhaustiva del $K$. Hurūšỳūšs con los otros testimonios hispanos de la Cosmografía, resultados que pueden arrojar más luz sobre la difusión peninsular de este tratado geográfico. A modo de introducción, esta confrontación nos enseña, por un lado, que el problema de la relación entre las versiones del $K$. Hurūšiyūšs y de los otros no es tan simple como lo planteaba Díaz y Díaz; y, por otro, que el texto incluido en la Crónica Pseudo Isidoriana no puede depender del $K$. Hurūšiyū̌s, al menos no de la recensión que se conserva en la Universidad de Columbia, y, por tanto, en este trabajo sí será tenido en cuenta.

\section{UNA VERSIÓN ÁRABE DE LA COSMOGRAFÍA. SU RELACIÓN CON LOS OTROS TESTIMONIOS}

El manuscrito de Columbia contiene una traducción árabe de las Historiae adversus paganos de Orosio interpolada con material procedente de varias fuentes latinas, entre las que destacan la Biblia, en una versión Vulgata, y la Chronica maiora de Isidoro de Sevilla. Junto con estas obras, el mozárabe autor de la traducción, cuyo nombre tal vez sea Ḥaf̣ al-Qūṭ̣ ${ }^{10}$, utilizó varias fuentes más que le sirvieron para completar y continuar la información proporcionada por las Historias de Orosio. Una de estas fuentes secundarias fue la Cosmografía de Julio Honorio, que sirvió al traductor para completar la sección geográfica incluida en el extenso capítulo 2 del Libro I de las Historias, que en el texto árabe ocupa dos

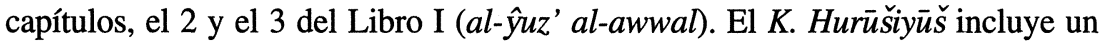
nuevo capítulo geográfico, el $4{ }^{11}$, cuyo título reza: Al-Bāb al-rābi ' min al-ŷuz' alawwal 'alà mā waŷadtu fi dawāwin Yüliyuš Qayșar (Capítulo 4 del Libro I, contiene lo que hallé en los archivos de Julio César). Así comienza este capítulo:

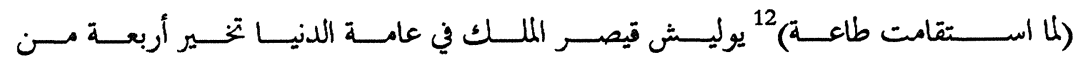

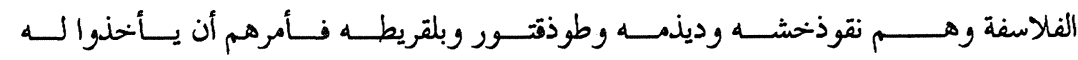

\footnotetext{
${ }^{10}$ Expongo las razones que me llevaron a plantear esta hipótesis en el artículo «A Possible Author of the Arabic Translation of Orosius' Historiae», Al-Masāq 13 (en prensa).

${ }^{11}$ Fols. $11 \mathrm{v}-14 \mathrm{v} / 20-26$.

${ }^{12}$ Las palabras entre paréntesis, ilegibles en el manuscrito de Columbia, las he tomado del Kitāb al-Jitat de al-Maqrīzī (El Cairo, 766-845/1364-1442), cuya versión es prácticamente idéntica a la del K. Hurüšiyüšs, fuente expresa de este pasaje (cf. El-Mawā' 'iz wa'l-i'tibär fi dhikr el-khitat wa'l-äthār, ed. G. Wiet, El Cairo, 1911-1924, vol. I, 37; Description topographique et historique de l'Égypte, trad. U. Bouriant, París, 1895-1900, 28).
} 


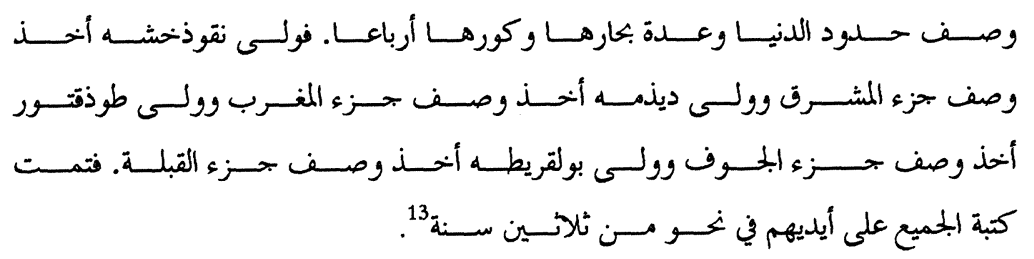

A continuación, el $K$. Hurūšiyūš informa del número de mares, de todo el orbe primero y de cada una de las partes después, de islas, montes, buldān (= países, regiones; provinciae en la Cosmografía), kuwar (= comarcas, aldeas; oppi$d a$ en la Cosmografía) y, finalmente, ríos. Veamos, a modo de ejemplo, el fragmento relativo a las islas:

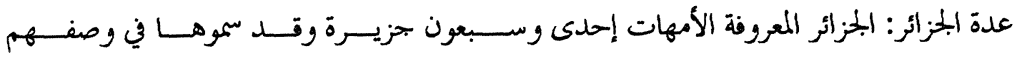

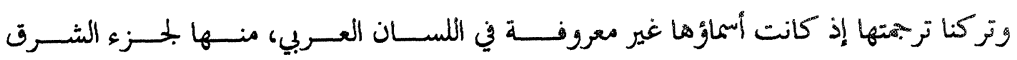

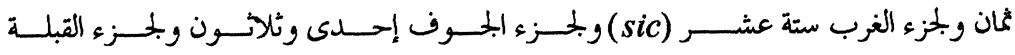

$$
\begin{aligned}
& \text { ست عشــرة }
\end{aligned}
$$

Con ese wa-taraknā tarŷamata-hā id kānat asmā'u-hā gayr ma'rūfa fi l-lisān al-'arabī (no los vamos a traducir por no ser conocidos sus nombres en lengua árabe) se evita el traductor el pesado trabajo que supone la transcripción de las largas listas de topónimos que componen la Cosmografía ${ }^{15}$. Sólo de los ríos ofrece el $K$. Hurūšiyūš más información: lugar de nacimiento y desembocadura, número de millas que recorre cada río, etc.

${ }^{13}$ Hur. I, fol. 11v/20, §56. Traducción: «Cuando el poder del rey Yūliyuš Qayṣar se consolidó en todo el mundo, [éste] eligió a cuatro filósofos: Niqūdijšuh, Dīdamuh, Tawd.qtūr y Buliqrītuh Les ordenó acometer para él la descripción de los límites del orbe [dividido] en cuatro partes, así como el número de sus mares y sus comarcas. A Niqūdijšuh le ordenó describir la parte oriental, a Dīdamuh la parte occidental, a Ṭawd.qtūr la septentrional y a Būliqrītuh la meridional. Tardaron unos treinta años en registrarlo todo".

${ }^{14}$ Hur. I, fol. 11v/20, §58. Traducción: «Número de islas: las principales islas conocidas son setenta y una. Al describirlas dan su nombre, pero nosotros no los vamos a traducir por no ser conocidos sus nombres en lengua árabe. De ellas, ocho pertenecen a la parte oriental, dieciséis a la occidental, treinta y una a la septentrional y dieciséis a la meridional».

${ }^{15}$ En efecto, como se verá en seguida, la Cosmografía es, con la excepción de los ríos, un simple catálogo de nombres de mares, islas, montes, provincias, ciudades y pueblos. 
La fuente de este capítulo del $K$. Hurüšiyūšs es, sin ningún género de dudas, el tratado geográfico conocido como Cosmographia Iulii Honorii. Sobre el autor de la Cosmografía, «Iulius Honorius magister» ${ }^{16}$, apenas sabemos nada. No se conoce su patria ${ }^{17}$. Tampoco se sabe cuándo vivió exactamente. Sólo se sabe con certeza que es anterior a Casiodoro (m. s. vI), quien cita el tratado del cosmógrafo «Iulii Oratoris» entre aquellos que debían ser leídos por los monjes ${ }^{18}$, posiblemente del siglo $\mathrm{v}^{19}$.

La Cosmografía de Julio Honorio, que, en palabras de M. L. W. Laistner, supuso para la geografía lo que la labor de los epitomadores supuso para la historia ${ }^{20}$, contiene una relación de nombres de mares, islas, montes, provincias, ciudades, ríos - de cada río dice, además, dónde nace y desemboca, y, en algunos casos, da información adicional-y pueblos (gentes) de cada una de las cuatro partes del mundo, empezando por la parte oriental para seguir con la occidental, la septentrional y, finalmente, la meridional.

Riese, editor de la Cosmografía, distingue dos recensiones de la obra, $A$ y $B^{21}$, que presentan multitud de diferencias entre sí. Riese considera genuina de Julio Honorio la recensión $A^{22}$, que estaría representada por un único manuscrito ${ }^{23}$, mientras que todos los demás pertenecerían a la recensión $B^{24}$. Una de las diferencias más importantes entre las dos recensiones es la introducción de la recensión $B$, no incluida en $A$, que cuenta cómo la descripción del orbe fue realizada por cuatro sabios siendo cónsules Julio César y Marco Antonio (Iulio Caesare et Marco Antoni[n]o consulibus omnis orbis peragratus est per sapientissimos et electos viros quattuor), informa de los años, meses y días que se tardó en medir cada una

16 Cosmogr., ed. Riese, 55.

17 Pertz opinaba que era hispano (De Cosmographia Ethici Libri Tres, Berlín, 1853, 30). Riese apuntaba la posibilidad de que fuera originario de Italia (Geographi Latini minores, XXII).

18 Cassiod., Inst. I, 25, 1 (Cassiodori Senatoris Institutiones, ed. R. A. B. Mynors, Oxford, 1937, 66).

19 Vid. Riese, Geographi, XXI; Díaz y Díaz, «Cosmografía», 331.

20 Thought and Letters in Western Europe A.D. 500 to 900, Londres, 1931, 20.

${ }^{21}$ El panorama que presenta Pertz es mucho más complejo que el ofrecido por Riese, pues aquél se basaba en un número mayor de códices, algunos de ellos bastante tardíos. Pertz, por ejemplo, distinguía una recensión más de la Cosmografía. Esta tercera recensión, que procedería de $B$, se caracterizaría, entre otros aspectos, por la incorporación de la sección geográfica de las Historias de Orosio (véase Pertz, De Cosmographia Ethici, 45 y ss.). Sin embargo, la división de Pertz no afecta a los testimonios que nos interesan; me basaré, por tanto, en la división más simple que presenta Riese.

${ }^{22}$ Geographi, XXII. De la misma opinión era Pertz (De Cosmographia Ethici, passim, por ejemplo, 21).

${ }^{23}$ Parisinus $4808(A)$, del siglo vi según Pertz (De Cosmographi Ethici, 21-22) y Riese (Geographi, XXXVI-XXXVII), del IX según Díaz y Díaz («Cosmografía», 331).

${ }^{24}$ Sobre los mss. de la recensión $B$, véase Riese, Geographi, XXXVII-XXXIX. Los más antiguos son el Veronensis $2(V)$, del siglo VI o VII, y el Parisinus 10318 olim Salmasianus $(S)$, del siglo VII-VIII. 
de las regiones del mundo (oriental, occidental, septentrional y meridional), así como del número de mares, islas, montes, provincias, ciudades, ríos y pueblos de todo el orbe primero, y de cada región después ${ }^{25}$. Además de esta introducción, las dos recensiones se diferencian en varios aspectos, entre los que cabe destacar:

- La recensión $B$ siempre consigna el número de millas que recorre cada río desde su nacimiento hasta su desembocadura, mientras que $A$ ofrece este dato sólo en el caso de algunos ríos.

- La recensión $B$ incluye algunos ríos que no aparecen en $A$, como el Betis ${ }^{26} \mathrm{o}$ el Tíber ${ }^{27}$.

- En $B$ el río Eurotas aparece después del Alfeo ${ }^{28}$, y en $A$ después del Corestes ${ }^{29}$.

- La descripción del recorrido de algunos ríos, como el Nilo, es sensiblemente más larga en $B$ que en $A$.

De acuerdo con la división de Riese, la versión incluida en el $K$. Hurūšìūus pertenecería, sin duda alguna, a la recensión $B$. El texto árabe contiene no sólo la introducción característica de $B$, sino los demás elementos que distinguen a esta recensión de $A$ : el $K$. Hurūšiyūšs siempre consigna el número de millas que recorren los ríos; el texto árabe incluye los ríos Betis/Bi $\underline{t}^{30}$ y Tíber/Tibar ${ }^{31}$; como en $B$, el río Eurotas/.rūziyuš aparece después del Alfeo/.lbiyū̌s ${ }^{32}$; por lo que respecta a la descripción de los ríos, la versión del $K$. Hurūšìyūšs siempre está más próxima a la de la recensión $B$, aun no siendo idénticas, que a la de $A^{33}$.

Fue $B$, sin duda, la recensión de la Cosmografía que se difundió en la Península, como demuestra el contenido del $K$. Hurüšyū̌š, y de los demás representantes hispanos:

- El Códice Ovetense de El Escorial conserva el texto incompleto de la Cosmografía. Los folios perdidos - un folio en medio y uno o dos al final- contenían el final de la región occidental (final de los ríos y pueblos), el principio de

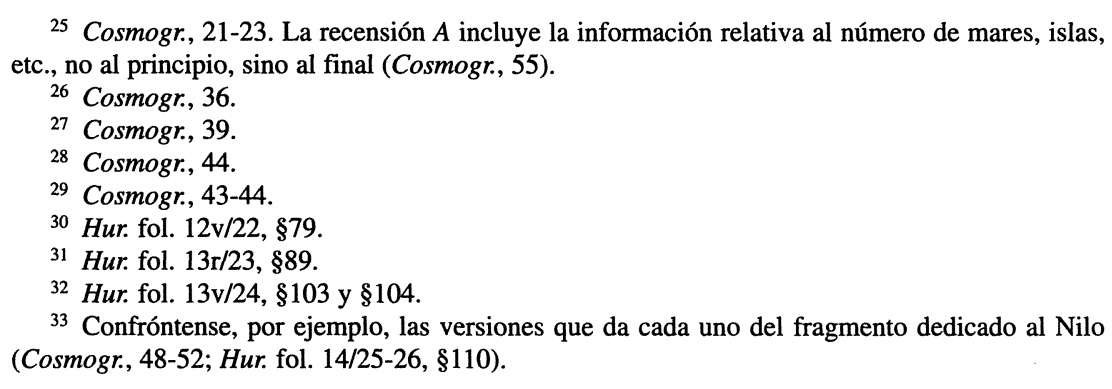


la septentrional (mares, islas, ciudades y principio de los montes) y el final de la meridional (ríos y pueblos). En la parte conservada hay que destacar la omisión de la información relativa al número de mares, islas, etc., de la región septentrional $^{34}$.

- La Crónica de Albelda incluye la introducción de la recensión $B$ y las millas que recorren cuatro ríos hispanos: Betis, Tajo, Miño y Ebro ${ }^{35}$.

- La Crónica Pseudo Isidoriana informa del nombre de los sabios encargados de medir el orbe junto con la parte asignada a cada uno, así como del tiempo que tardaron en llevar a cabo su trabajo ${ }^{36}$.

A simple vista resulta obvio que todos los testimonios hispanos pertenecen a la recensión $B$, pues los cuatro contienen toda o parte de la introducción característica de esta recensión. Como observó Díaz y Díaz, es evidente además que existe cierta relación entre ellos. Para llegar a esta conclusión, Díaz y Díaz se basaba únicamente en la lección similar que del nombre de uno de los sabios ofrecen los cuatro: el códice Ovetense lee «Nicodoxo» donde la Crónica de Albelda lee «Nicodoso», el K. Hurūšiyūš «Niqūdijšuh» y la Crónica Pseudo Isidoriana «Nochodoxus» ${ }^{37}$. Esta lección sólo la dan estos testimonios, mientras

\footnotetext{
34 En folios 55v/61v del códice, salvo el fol. 59, que es añadido. En el folio 55v hay una nota marginal en árabe, traducción del pasaje que informa del número de años, meses y días que se tardó en medir cada una de las regiones del mundo (reproducida en Barceló, C., y Labarta, A., Números y cifras en los documentos arábigo-hispanos, Córdoba, 1988, 55). La información aparece dispuesta en tres columnas, la primera (empezando por la derecha) para los años ( سنو), la segun-

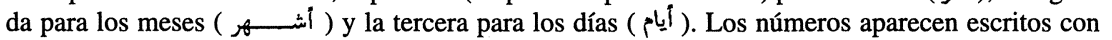
cifras rumíes, que derivan de las cifras coptas cursivas, variante del sistema numérico griego ( $c f$. tablas en Mallon, A., Grammaire copte, Beirut, 1926 [3. a ed.], 226bis; y González Palencia, A., Los mozárabes de Toledo en los siglos XII y XIII, volumen preliminar, Madrid, 1930, 48). La utilización de estas cifras en la Península está documentada a partir de finales del siglo XII. Sobre las cifras rumíes, además de los trabajos citados, véase: Colin, G. S., «De l'origine grecque des 'chiffres de Fès' et de nos 'chiffres arabes', Journal Asiatique 222 (1933), 193-215; Levi Della Vida, G., «Appunti e quesiti di storia letteraria araba», Rivista degli Studi Orientali 14 (1934), 281-283; Sánchez Pérez, J. A., «Sobre las cifras rumíes», Al-Andalus 3 (1935), 97-125; Ritter, H., «Griechisch-Koptische ziffern in Arabischen manuskripten», Rivista degli Studi Orientali 16 (1936), 212-213, seguido por una nota de Levi Della Vida.

35 Ed. Flórez, 433-434; ed. Bonnaz, 10-11. El códice Albeldense no contiene la introducción de la Crónica de Albelda, donde se incluye el material procedente de la Cosmografía, y comienza directamente en el Ordo romanorum (vid. Bonnaz, Chroniques Asturiennes, XXX). Tampoco el Complutense ofrece la información relativa a los ríos hispanos. Por tanto, para este estudio sólo nos sirve el Emilianense y, en parte, el Complutense.

36 Ed. Mommsen, 38; ed. Benito Vidal, 20.

37 Ovetense, fol. 55v; Albelda, ed. Bonnaz, 10; Hur. fol. 11v/20, §56; Ps.Isid., ed. Benito Vidal, 20. Díaz y Díaz tomó la lección que da el $K$. Hurūšiyūš del artículo de Levi della Vida, «La traduzione araba delle Storie di Orosio» (1954), 269 (rep. en Note, 88-89).
} 
que otros leen «Nicodemo», «Nicodomo» o «Nicodoro» ${ }^{38}$. Díaz y Díaz se apoyaba exclusivamente en este ejemplo para demostrar la «innegable vinculación» del K. Hurūšsiyūš con el códice Ovetense y la Crónica de Albelda ${ }^{39}$.

La cuestión, sin embargo, se complica al confrontar estos tres textos. A Díaz y Díaz, por ejemplo, no le fue posible observar que el $K$. Hurūšiyūš no comparte con el Ovetense $(O)$ y Albelda la significativa ausencia del Duero entre los ríos occidentales, ausencia que también se da en el otro representante de la recensión $B$ estudiado por Díaz y Díaz en su artículo, el códice Parisino $4871(C)$, del siglo X-XI ${ }^{40}$. La ausencia del Duero sería una de las principales características de una de las dos familias de la recensión $B$, familia a la que pertenecerían $O$, Albelda y $C$, y que, según Díaz y Díaz, «está muy cerca de $A{ }^{41}$. El K. Hurūšìūšs sí incluye el fragmento dedicado al Duero ${ }^{42}$, pero si, como creo, la adición del Duero fue posterior, es probable que la copia en que se basa el $K$. Hurūšiyūšs, que llamaré $H$, pertenezca a la misma familia que $O, C$ y Albelda. En el K. Hurūšiyūš el Duero aparece entre el Ebro y el Ródano, es decir, en sitio diferente del resto de los representantes de ambas recensiones, que lo incluyen entre el Tajo y el Miño ${ }^{43}$. El fragmento del $K$. Hurūšiyūš relativo al Duero es, como veremos en seguida, idéntico al que aparece en los Excerpta ex libro glossarum editados por Goetz ${ }^{44}$. Según todo parece indicar, el copista del códice en que se basa la versión del $K$. Hurūšiyūš, o tal vez el propio traductor, disponía de un glosario latino, que evidentemente derivaba del Liber glossarum, al que recurrió al apercibirse de la falta del Duero entre los ríos hispanos.

\footnotetext{
38 Cosmogr., 21.

39 «Cosmografía», 338. 333.

40 Sobre este códice, véase Riese, Geographi, XXXVIII-XXXIX; Díaz y Díaz, «Cosmografía»,

41 «Cosmografía», 335; véase también id., «El Códice Ovetense», 40.

${ }^{42}$ Hur. fol. 13r/23, §83. En «Fuentes latinas de los geógrafos arabes», Al-Andalus 32 (1967), 246, J. Vallvé recoge un fragmento sobre el Duero idéntico al del $K$. Hurüšiyū̌š. El texto lo ha tomado de R. Grosse (ed.), Las fuentes desde César hasta el siglo v d. J.C. (Fontes Hispaniae antiquae, 8), Barcelona, 1959, 443

${ }^{43}$ Cosmogr., 36.

${ }^{44}$ En Corpus glossariorum Latinorum, V, Leipzig, 1894, 191. El Liber glossarum es un gran léxico compuesto, en opinión de Goetz, en Hispania entre los años 690 y 750 (Corpus glossariorum Latinorum, V, XX); véase también Sánchez-Albornoz, C., Fuentes latinas de la historia romana de Rasis, Buenos Aires, 1942 (rep. en Investigaciones sobre historiografía hispana medieval, 332 , n. 137). No todos los investigadores comparten esta opinión. Lindsay, por ejemplo, apunta la posibilidad de que sea originario de Corbie (Glossaria Latina, vol. I, París, 1926, 8), tesis apoyada por G. Barbero en «Contributi allo studio del Liber glossarum», Aevum (1990), 151-152, donde da a conocer otras hipótesis al respecto.
} 


\begin{tabular}{|c|c|c|c|}
\hline $\operatorname{Rec} \cdot A$ & Rec. $B$ & L. glossarum & K. Hurüšiyüš \\
\hline $\begin{array}{l}\text { Fluvius Durius } \\
\text { nascitur in campis } \\
\text { Hispaniae. Egerit } \\
\text { in oceanum } \\
\text { occidentalem. }\end{array}$ & $\begin{array}{l}\text { Fluvius Durius } \\
\text { nascitur in } \\
\text { Carpitania exiens } \\
\text { de monte Caia } \\
\text { iuxta Pyrenaeum. } \\
\text { Currit per campos } \\
\text { Hispaniae } \\
\text { inlustrans } \\
\text { paramum. Deinde } \\
\text { disrumpens loca } \\
\text { montuosa, dividens } \\
\text { Galliciam et } \\
\text { Lusitaniam, ducens } \\
\text { aquas multas valde, } \\
\text { occidit in oceano } \\
\text { occidentali. Currit } \\
\text { milia CCCCXCV. }\end{array}$ & $\begin{array}{l}\text { Durius fluvius } \\
\text { nascitur in campis } \\
\text { Hispani(a)e, } \\
\text { infundit in oceano } \\
\text { Occidentali inter } \\
\text { duos oppidos, post } \\
\text { occurrit milia } \\
\text { quingenta } \\
\text { octoginta. }\end{array}$ & 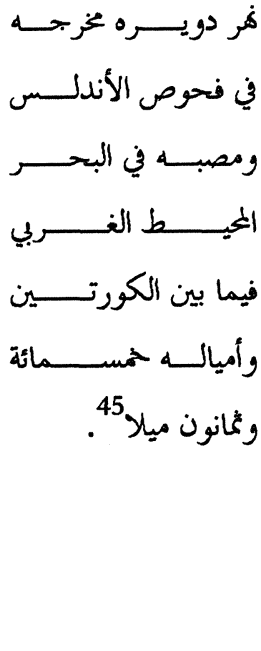 \\
\hline
\end{tabular}

Como se puede observar, el texto del $K$. Hurūšiyūš es idéntico al del Liber glossarum, e incluso, en este caso, su versión está más próxima a la del único representante de la recensión $A$, Parisinus 4808 , que a la que ofrecen otros testimonios de $B$.

En suma, todo parece indicar que $H$ dependía del mismo arquetipo que $O$, Albelda y $C$, que se caracterizaba por la ausencia del Duero, ausencia que fue enmendada por $H$ o por un subarquetipo del que dependía $H$.

Varios ejemplos más confirman la hipótesis de que $H$ pertenecía a la misma familia que $O, C$ y Albelda. Pero, antes de ver algunos de estos ejemplos, he de hacer una advertencia importante: en el aparato crítico de la edición de Riese, las variantes que el editor atribuye al códice Ovetense no corresponden en realidad a las lecciones que da este códice, sino a las de la Crónica de Albelda según la edición de Flórez, que se basa en el códice Emilianense ${ }^{46}$. Resulta sospechoso el hecho de que Riese dé las variantes de $O$ sólo en aquellas partes incluidas también en la Crónica de Albelda, esto es, la introducción y los cuatro ríos hispanos. La sospecha se convierte en certidumbre cuando se confrontan ambos textos. He aquí algunos ejemplos: según el códice Ovetense, las islas de todo el mundo son

45 Traducción: «El río Dūyruh nace en los campos de al-Andalus y desemboca en el océano occidental, entre las dos comarcas [¿o aldeas?]. Recorre quinientas ochenta millas».

46 Sobre los mss. de Albelda, véase supra, n. 4. 
74, mientras que Riese le atribuye 79 , variante de Albelda ${ }^{47}$; con respecto al número de ríos de la región meridional, el Ovetense lee 16, pero según la edición de Riese leería 6, como Albelda ${ }^{48}$; según el Ovetense, el Tajo recorre 302 millas, el Miño 310 y el Ebro 204, mientras que según Albelda el primero recorre 602, el segundo 313 y el otro 304, variantes que Riese atribuye al Ovetense ${ }^{49}$.

Díaz y Díaz ya observó que Riese atribuía una lectura errónea al Ovetense, en concreto, a propósito del número de años que tardó en medirse la parte meridional: $O$ da 24, «el Salmasiano lee 32 y los demás 22 (lectura que Riese atribuye al Ovetense)» ${ }^{50}$. Sin embargo, parece que Díaz y Díaz no se dio cuenta de por qué Riese atribuyó esa lectura al Ovetense, de dónde la tomó. Es más, aunque - a diferencia de Riese- Díaz y Díaz indudablemente ha visto el códice Ovetense, parece basarse en el aparato crítico de la edición de Riese ${ }^{51}$, y no directamente en el manuscrito, cuando, después de transcribir el fragmento introductorio de la Crónica de Albelda según el códice Emilianense, afirma que la confrontación de este texto con el del Ovetense muestra «que la coincidencia en un punto tan frágil como los números es casi total» ${ }^{52}$. Después de haber visto in situ el códice Ovetense, puedo afirmar que la coincidencia entre los números del Ovetense y la Crónica de Albelda no es total, ni siquiera «casi total», sino normal entre dos manuscritos que, en efecto, pertenecen a una misma familia, pero parecen derivar de subarquetipos distintos.

Se basara Díaz y Díaz en la edición de Riese o directamente en el manuscrito Ovetense para comparar las versiones incluidas en este códice y en la Crónica de Albelda, lo cierto es que existe una clara vinculación entre estos dos textos. Es evidente también la estrecha relación de $O$ y Albelda con $C$, así como la relación, no tan estrecha en este caso, de esos tres con el $K$. Hurüšyuūš. Los cuatro parecen depender de un arquetipo común del que, aparte de la ausencia del Duero, proceden varias lecciones que los unen, separándolos, a su vez, de otros testimonios. Por ejemplo, el número de montes de la región occidental es 9 según la recensión $B, 15$ según $O, C$, Albelda y Hurūšiy ūšš ${ }^{53}$; con respecto al número de ciudades de la región meridional, la recensión $B$ lee 46, donde $O$ y $C$ leen 61 , y Albelda y Hurūšìū̌š $62^{54}$.

47 Cosmogr., 22, 1. 7; Ovetense, fol. 55v; Albelda, ed. Bonnaz, 10.

48 Cosmogr., 23, 1. 6; Ovetense, fol. 55v; Albelda, 10.

49 Cosmogr., 36-37; Ovetense, fol. 58v; Albelda, 11.

50 «Cosmografía», 335.

51 Yo misma he tenido que confiar en la edición de Riese, y de ahí he tomado las variantes del ms. $C$.

52 «Cosmografía», 337.

53 Cosmogr., 23, 1. 1; Ovetense, fol. 55v; Albelda, 10; Hur. fol. 11v/20, §59.

54 Cosmogr., 23, 1. 6; Ovetense, fol. 55v; Albelda, 10; Hur. fol. 11v/20, §61. 
De lo dicho hasta aquí podrían extraerse las siguientes conclusiones: dentro de la recensión $B, O$, Albelda, $C$ y Hurūšiyūš pertenecerían a una misma familia, que se distingue por la ausencia del Duero y por otras variantes comunes que los separan de los otros representantes de la misma recensión; los tres testimonios hispanos de esta familia, $O$, Albelda y Hurūšiȳǔš, pertenecerían a su vez a una misma subfamilia, que se caracteriza por la lección Nicodox(s)o/Niqūdijšuh. Díaz y Díaz llegaba a afirmar que la Cosmografía fue conocida en la Península sólo a través del Ovetense, es decir, que de este texto derivaban directa o indirectamente las versiones incluidas en la Crónica de Albelda y en el K. Hurūšìū̌š. Como se ha dicho, es evidente la vinculación del Ovetense no sólo con los otros testimonios hispanos sino también con el códice $C^{55}$, pero la mencionada ausencia en el Ovetense de la información relativa al número de mares, islas, etc., de la región septentrional, información que sí ofrecen todos los demás, obliga a rechazar la hipótesis de Díaz y Díaz. Por otra parte, la inclusión en $C$ y Albelda de lecciones que los acercan entre sí o a otros testimonios de la recensión $B$ en contra precisamente del Ovetense lleva a pensar que, si bien es innegable que tanto $C$ como Albelda dependen, directa o indirectamente, de la copia que sirvió de base al texto del Ovetense, es asimismo obvio que no proceden de este códice, ni directa ni indirectamente.

Pero dejemos el problema de la relación entre $O$, Albelda y $C$ para los especialistas, y centrémonos en la versión del $K$. Hurūšiyūš. Mediante una profunda comparación de este texto con los otros representantes de su misma familia se observa que a veces dos o tres de ellos dan lecciones comunes en contra del $K$. Hurūšỳū̌š, mientras que otras veces éste se asemeja a uno o dos de los anteriores en contra del otro o los otros. Sin embargo, en la mayoría de los casos, las variantes no son significativas, pues parecen deberse a una mala lectura de un número romano: ante un LXXIIII es fácil equivocarse - la propia experiencia me lo ha enseñado- y leer 73 ó 63 ó 64 (y todas las combinaciones posibles). Así, a propósito del número de islas de la región meridional, $O, C$ y Hurüšiyūš leen 16, donde Albelda lee $17^{56}$; según $C$ y Albelda, la región meridional consta de 13 provincias, según $O$ de 14 , y según Hurūšiyū̌š de $12^{57}$; en cuanto a las ciudades de la misma región, Albelda y Hurūšiyūš leen 62 donde $O$ y $C$ leen $61^{58}$.

\footnotetext{
${ }^{55}$ De hecho, el stemma que ofrece Pertz sugiere que $C$ procedía de $O$ (De Cosmographia Ethici, 41). Como se verá inmediatamente, $C$ no puede depender del Ovetense, aunque «sí de un gemelo suyo» (Díaz y Díaz, «Cosmografía», 335).

${ }^{56}$ Cosmogr., 23, 1. 5; Ovetense, fol. 55v; Albelda, ed. Bonnaz, 10; Hur. fol. 11v/20, §58.

57 Cosmogr., 23, 1. 6; Ovetense, fol. 55v; Albelda, 10; Hur, fol. 11v/20, §60.

${ }^{58}$ Cosmogr., 23, 1. 6; Ovetense, fol. 55v; Albelda, 10; Hur. fol. 11v/20, §61.
} 
Sin embargo, la confrontación del K. Hurūšsiyūš no sólo con los tres testimonios de su misma familia, sino también con los otros representantes de la recensión $B$ nos enseña que, en numerosas ocasiones, la versión del texto árabe se acerca más a esos otros testimonios que a los de su propia familia y, en muchos de estos casos, las variantes sí son significativas. Así, a propósito del número de montes de todo el orbe $O, C$ y Albelda leen 41, mientras que Hurūšyiȳš lee 36, variante más cercana a los 35 de otros representantes más antiguos de la recensión $B^{59}$; con respecto al número de provincias de la región occidental, Hurūšiȳǔš da 25 , donde $O, C$ y Albelda leen $27^{60}$. Hay ejemplos más claros en la parte relativa a la descripción de los ríos (en esta parte no podemos contar con Albelda): según la recensión $B$ y Hurūšiyū̌s, el Cortacie (Hur: Q.rtāw.y.h) recorre 917 millas, mientras que según $O$ recorre 63 (¿o 57?) ${ }^{61}$ y según $C, 57^{62}$; con respecto a las millas del río Alibotra (ms. O: aliuotra; Hur: .lïfanā), B y Hurūšiyū̌̌s leen 416, donde $O$ y $C$ leen $442{ }^{63}$; según Hurū šiy $\bar{u} s ̌$ «los tres ríos» ${ }^{64}$ recorren 202 millas, el mismo número que da $B$, frente a 302 de $O$, y 402 de $C^{65}$.

En resumen, $O, C$ y Hurūšiyūš parecen pertenecer a una misma familia dentro de la recensión $B$, pero, en varias ocasiones, mientras que las lecciones de $O$ y $C$ son iguales o parecidas, el $K$. Hurūšsiyūš da una lectura que lo aparta de esos dos, acercándolo a otros testimonios de esta recensión. ¿Cómo podríamos explicar estos hechos? La única explicación plausible es que $H, O, C$ y Albelda deriven de un mismo arquetipo y que $H$, por un lado, y $O, C$ y Albelda, por otro, dependan de subarquetipos distintos. Del arquetipo común procedería la ausencia del Duero, la lección «Nicodox(s)o» y todas las variantes comunes a ellos cuatro en contra de los otros. Sin embargo, $C$ no comparte con los otros tres uno de esos elementos: $C$ no lee «Nicodox(s)o» sino «Nicodoro», lección que tampoco coincide con las de otros testimonios de la recensión $B^{66}$. Teniendo en cuenta que $C$ es una copia bastante tardía, es muy posible que $C$ proceda del arquetipo que daba esa lección, y que en algún momento de la transmisión la «s» se cambiara en «r», modificación que pudo deberse al propio copista de $C$.

\footnotetext{
59 Cosmogr., 22, 1. 8; Ovetense, fol. 55v; Albelda, 10; Hur. fol. 11v/20, §59.

60 Cosmogr., 23, 1. 2; Ovetense, fol. 55v; Albelda, 10; Hur. fol. 11v/20, §60.

${ }^{61}$ El número en el ms. no está muy claro. En un primer momento entendí LXIII, pero tal vez haya que leer LVII, variante de $C$.

62 Cosmogr., 29, 1. 20; Ovetense, fol. 57r; Hur. fol. 12v/22, §70.

63 Cosmogr., 30, 1. 10; Ovetense, fol. 57r; Hur. fol. 12v/22, §73.

64 Hur: «al-talāta al-anhār majraŷu-hā fi balad al-Habaša» (los tres ríos nacen en Etiopía...). Cosmogr: «flumina tria Ichthyophagi dicta» (ed.); «flumina tria ethiopagi dicta» (ms. V); «fluvius inatria ictio pagi dicta» (ms. $O$ ).

${ }^{65}$ Cosmogr., 30, 1. 12; Ovetense, fol. 57r; Hur. fol. 12v/22, §74.

66 Cosmogr., 21.
} 
El stemma que reflejaría esta relación sería el siguiente:

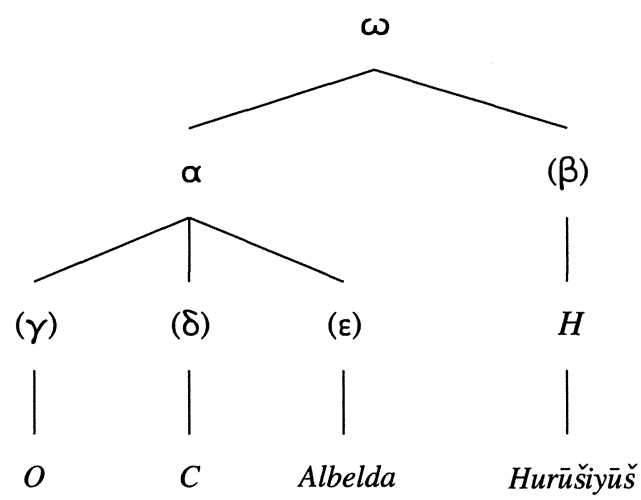

El arquetipo $\omega$ presentaría los elementos comunes que distinguen a $O, C$, Albelda y $H$ frente a los demás representantes de la recensión $B . O, C$ y Albelda dependerían directa o indirectamente de un subarquetipo $\alpha$ que presentaría las variantes que unen a estos tres frente a $H . \beta, \gamma, \delta$ y $\varepsilon$ representarían los posibles subarquetipos intermedios.

En conclusión, el testimonio que nos ofrece el $K$. Hurūšiyūš sugiere que al menos dos copias de la Cosmografía circulaban en la Península: de una de ellas proceden, directa o indirectamente, las versiones incluidas en $O$, Albelda y $C$; la otra -emparentada con aquélla, pero no estrechamente- circuló a finales del siglo IX entre los mozárabes de Córdoba y sirvió de base para la versión del $K$. Hurūšìūšs.

\section{LA VERSIÓN DE LA CRÓNICA PSEUDO ISIDORIANA}

De la copia utilizada para el $K$. Hurūšiyūš podría derivar también la versión del otro representante hispano de la Cosmografía, que, por su contenido, no nos servía hasta ahora, la Crónica Pseudo Isidoriana. Como se dijo al principio, según Díaz y Díaz, el texto procedente de la Cosmografía inserto en esta obra dependería del K. Hurūšiyūš ${ }^{67}$. Sin embargo, un hecho significativo excluye por completo la posibilidad de que el material de la Pseudo Isidoriana proceda del

67 «Cosmografía», 338. 
texto árabe, al menos de la recensión que se conserva en Columbia: la Pseudo Isidoriana incluye el fragmento que informa del tiempo que se invirtió en medir cada una de las regiones del mundo ${ }^{68}$, mientras que, como se ha dicho, el $K$. Hurūšiyūš se limita a decir que los sabios realizaron el trabajo en unos treinta años ${ }^{69}$. La copia que se conserva en Columbia parece bastante tardía, tal vez del siglo XIII o XIV ${ }^{70}$, y cabría la posibilidad de que una copia anterior de la traducción, la original quizá, incluyera este fragmento, y que de esta copia lo tomara el autor de la Crónica Pseudo Isidoriana. No he encontrado ninguna evidencia que apoye o se oponga a esta posibilidad. Sin embargo, de mis investigaciones en torno a la relación del K. Hurūšiyūš, la Crónica Pseudo Isidoriana y los Ajbār mulūk al-Andalus de al-Rāzī (m. 955), he llegado a la conclusión (provisional por el momento) de que el autor de la Pseudo Isidoriana no conoció el $K$. Hurūšiyū̌s, aunque es muy probable que ambas obras se basen en una fuente común $^{71}$.

Centrémonos ahora en el material procedente de la Cosmografía inserto en la Crónica Pseudo Isidoriana. Como se dijo al principio, esta obra sólo informa del nombre de los sabios (Nochodoxus, Ridimus, Pelagius, Todora), de la región del mundo asignada a cada uno y de los años $\left({ }^{(a)}\right.$, meses $\left({ }^{(m)}\right.$ y días $\left({ }^{d}\right)$ que se tardó en medir cada parte ${ }^{72}$. Como muestra la tabla siguiente, con respecto a esta última cuestión es evidente la relación entre la información de la Pseudo Isidoriana y la que ofrecen los otros testimonios de la recensión $B^{73}$, aunque en la Pseudo Isidoriana a cada parte se atribuye el tiempo de medición de la siguiente. Así, el

68 Ed. Mommsen, 380; ed. Benito Vidal, 20.

69 Hur. fol. $11 \mathrm{v} / 20, \$ 56$.

70 Véase, por ejemplo, Levi Della Vida, «La traduzione araba delle Storie di Orosio» (1954), 266 (rep. en Note, 86); Daiber, H., «Orosius' Historiae adversus Paganos in Arabischer Überlieferung», en Tradition and Re-interpretation in Jewish and Early Christian Literature. Essays in Honour of Jürgen C. H. Lebram, ed. J. W. van Henten et al., Leiden, 1986, 202; van Koningsveld, P. Sj., «Christian-Arabic Manuscripts from the Iberian Peninsula and North Africa: a Historical Interpretation», Al-Qantara XV (1994), 445.

71 Las dos contienen material procedente de las mismas fuentes, precisamente de obras que, como las Etimologías de Isidoro de Sevilla o la Cosmografía, fueron utilizadas como fuentes secundarias para la redacción del $K$. Hurū $\overline{s i y} \bar{u} \breve{s}$; sin embargo, pocas veces coinciden los datos y las noticias que de la misma fuente toman la Pseudo Isidoriana y el K. Hurūšiyūšs. La existencia de una fuente común - tal vez una compilación mozárabe de textos latinos - utilizada de forma independiente por los autores de las dos obras explicaría las semejanzas y divergencias que existen entre ellas. Sobre la posible existencia de una compilación mozárabe, véase, por ejemplo: SánchezAlbornoz, C., «Fuentes latinas de la historia romana de Rasis», en Investigaciones sobre historiografía hispana medieval, 327 y ss.; id., «San Isidoro, 'Rasis' y la Pseudo Isidoriana», 107-108; Menéndez Pidal, R., «Sobre la Crónica Pseudo Isidoriana», especialmente 9-10.

72 Ed. Mommsen, 380; ed. Benito Vidal, 20.

${ }^{73}$ Cosmogr., 21-22; Ovetense, fol. 55v; Albelda, ed. Bonnaz, 10. El artículo de Díaz y Díaz incluye la transcripción del fragmento del Ovetense («Cosmografía», 334). 
tiempo que, según este texto, tardó en medirse la región meridional, corresponde al tiempo que, según los otros, tardó en medirse la oriental; el tiempo de la oriental corresponde al de la parte occidental, y así sucesivamente.

\begin{tabular}{l|lllll} 
& Rec. $B$ & Ms. $O$ & Albelda & Ms. $C$ & Ps.Isid. \\
\hline E & $21^{\mathrm{a}}, 5^{\mathrm{m}}, 9^{\mathrm{d}}$ & $21,5,9$ & $22,2,8$ & $21,2,9$ & $36,3,17$ \\
O & $26^{\mathrm{a}}, 3^{\mathrm{m}}, 1^{\mathrm{d}}$ & $27,3,17$ & $26,3,17$ & $26,3,17$ & 29,8 \\
$\mathrm{~N}$ & $29^{\mathrm{a}}, 8^{\mathrm{m}}$ & 29,8 & 29,2 & 29,8 & $23,1,20$ \\
$\mathrm{~S}$ & $32^{\mathrm{a}}, 1^{\mathrm{m}}, 20^{\mathrm{d}}$ & $24,1,20$ & $22,1,30$ & 22,1 & $21,5,9$
\end{tabular}

Aunque en este lugar la Crónica Pseudo Isidoriana no da más información procedente de la Cosmografía, más adelante encontramos dos datos que también parecen tomados de este tratado: número de millas del Betis y del Tajo. Según la Pseudo Isidoriana, el Betis recorre 410 millas ${ }^{74}$. Y en este dato coincide con todos los demás testimonios ${ }^{75}$, con todos excepto con el $K$. Hurūšiyū̌̌s, que lee $310^{76}$. Con respecto al Tajo, en cambio, el número de millas que da la Pseudo

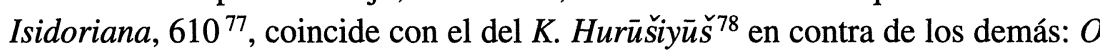
lee 302, C 402 y Albelda $602^{79}$. El hecho de que el dato de la longitud del Tajo sea idéntico en el $K$. Hurūšiyūš y la Pseudo Isidoriana en contra de los otros admite dos explicaciones: o bien ambos dependen de la misma copia, o bien uno de los dos se basa en el otro -lógicamente la Pseudo Isidoriana en el $K$. Hurūšiyūš. Sin embargo, parece oponerse a esta última posibilidad el hecho de que, con respecto al Betis, la Pseudo Isidoriana dé el mismo dato que todas las demás versiones en contra, precisamente, del $K$. Hurūšiyūš, lo cual podría tener, a su vez, varias explicaciones: el autor de la Pseudo Isidoriana tomó del texto árabe el dato de la longitud del Betis, pero, al copiarlo, él o un copista posterior, cometió un error y, por una afortunada casualidad, en su equivocación dio precisamente la lectura «correcta» según los otros testimonios; el error se debió al copista del texto árabe, es decir, la copia original del $K$. Hurūšiyūš daba el dato correcto, 410, y de ahí lo tomó la Pseudo Isidoriana; el autor de la Pseudo Isidoriana no lo tomó del $K$. Hurūš̌iyušs. Y, en mi opinión, esta última posibilidad es la más probable. Sin duda, es fácil leer CCCX donde en realidad dice

\footnotetext{
74 Ed. Mommsen, 381; ed. Benito Vidal, 22.

75 Cosmogr., 36; Ovetense, fol. 58v; Albelda, 11.

76 Hur. fol. $12 \mathrm{v} / 22, \S 79$.

77 Ed. Mommsen, 380; ed. Benito Vidal, 22.

78 Hur. fol. $12 \mathrm{v} / 22, \S 80$.

79 Cosmogr., 36; Ovetense, fol. 58v; Albelda, 11.
} 
CCCCX, pero no parece tan fácil leer ثلالمائــة وعشــرة (310) donde dice (410). Parece más probable, por tanto, que el error tuviera su origen en una mala lectura del texto latino que del árabe, es decir, que el error ya estuviera en la copia original del $K$. Hurūšiyūš, y no que el error se deba al copista de este texto, o al autor o copista de la Pseudo Isidoriana.

En resumen, según todo parece indicar, los autores del $K$. Hurūšiyūš y de la Crónica Pseudo Isidoriana se basaron en una misma versión de la Cosmografía de Julio Honorio, pero cada uno la utilizó de manera independiente, tomando en cada caso el material que le interesaba: prácticamente todo, salvo el tiempo exacto que tardaron los sabios en realizar su trabajo y las largas listas de topónimos en el caso del $K$. Hurūšiyū̌s; sólo el nombre de los sabios, el tiempo que tardaron y algún dato suelto en el caso de la Crónica Pseudo Isidoriana.

\section{CONCLUSIÓN}

Y poco más puedo añadir a la frase «esa difusión [de la Cosmografía de Julio Honorio] se dio y tuvo cierta importancia» que pone fin al artículo de Díaz y Díaz. A modo de recapitulación, el testimonio que nos ofrece el $K$. Hurūšiyū viene a confirmar algunas de las conclusiones generales a que había llegado Díaz y Díaz: fue $B$, sin duda, la recensión que se difundió en la Península; los cuatro representantes hispanos y, al menos, uno más, el códice Parisino 4871, parecen pertenecer a una misma familia dentro de esa recensión $B$; una copia circuló por el sur peninsular, donde fue utilizada por el autor del $K$. Hurū ̌̌ìȳuš.

A partir de este punto, los resultados obtenidos del análisis de la versión árabe y de la comparación de este texto con las otras versiones hispanas de la Cosmografía me obligan a discrepar de Díaz y Díaz: por una parte, el fragmento incluido en la Crónica Pseudo Isidoriana no depende, en mi opinión, del $K$. Hurū $̌ s i y \bar{u} \breve{s}$, aunque sí de una copia estrechamente relacionada con la que sirvió como base de la versión incluida en el texto árabe, probablemente la misma; por otra parte, esta copia no puede ser la misma utilizada para el fragmento incluido en el Ovetense, mucho menos el propio códice Ovetense, pues el $K$. Hurūšiyūš a veces ofrece lecturas más cercanas a otros testimonios de la recensión $B$ que a $O$. Todo apunta, en fin, a que por lo menos dos copias de la Cosmografía, procedentes de un mismo arquetipo, circularon en la Península: de una derivan, de manera independiente en mi opinión, las versiones del Ovetense y la Crónica de Albelda; de la otra, las del Kitāb Hurūšìū̌š y la Crónica Pseudo Isidoriana. 


\title{
RESUMEN
}

Este trabajo pretende ser una contribución al conocimiento de la difusión peninsular de la Cosmografía de Julio Honorio, a través del análisis de la versión incluida en el Kitāb Hurūšiȳūs - traducción árabe interpolada de las Historias contra los paganos de Orosio- y de la comparación de este texto con los otros testimonios hispanos de la Cosmografía: el Códice Ovetense de El Escorial, la Crónica de Albelda y la Crónica Pseudo Isidoriana.

\begin{abstract}
This article is a contribution to the knowledge of the diffusion of Iulius Honorius' Cosmography in the Iberian Peninsula, through an analysis of the version included in the Kitāa Hurūšiy ūš - the interpolated Arabic translation of Orosius' Histories against the Pagans-, and through comparing this text with the other Spanish testimonies of the Cosmography: the Codex Ovetensis of the library of El Escorial, the Crónica de Albelda, and the Crónica Pseudo Isidoriana.
\end{abstract}

